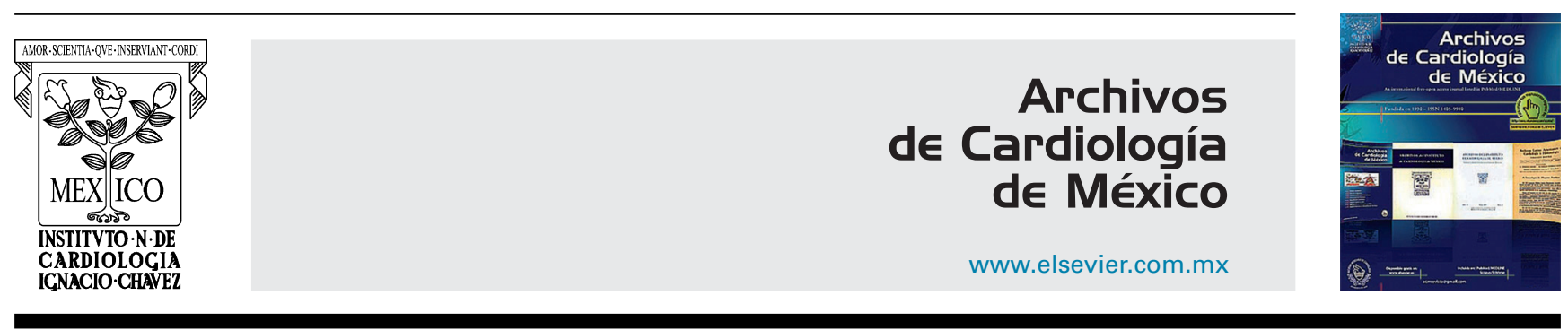

IMAGEN EN CARDIOLOGÍA

\title{
Calcificación masiva de la aurícula izquierda
}

\section{Massive left atrial calcification}

\section{Pablo Robles-Velasco*, Isabel Monedero-Sánchez, Yago González-Doforno y Maher Chichakli-Cela}

Unidad de Cardiología, Hospital Universitario Fundación Alcorcón, Alcorcón, España

Recibido el 10 de mayo de 2017; aceptado el 1 de septiembre de 2017

Mujer de 65 años de edad que ingresa por insuficiencia cardiaca de predominio derecho.

Previamente diagnosticada de estenosis mitral reumática severa, se había realizado un recambio valvular mitral por prótesis mecánica hacía 20 años. El ecocardiograma transtorácico y transesofágico realizados mostraron una prótesis normofuncionante, así como una hipertensión arterial pulmonar severa $(90 \mathrm{mmHg})$ junto a dilatación de cavidades derechas y disfunción sistólica del ventrículo derecho. La radiografía de tórax (figs. $1 \mathrm{~A}$ y $\mathrm{B}$ ) presentaba una calcificación lineal que seguía todo el contorno de la aurícula izquierda (Al), lo cual se confirmó en un TAC sin contraste que mostró calcificación tanto de la pared libre de la Al como del septo interauricular, e incluso de la orejuela izquierda y del aparato subvalvular mitral (fig. $1 C$ y D). La calcificación de la pared de la Al es una complicación infrecuente de la cardiopatía reumática ${ }^{1}$, reconociéndose
2 entidades: la aurícula de porcelana cuando se afectan el aparato mitral, la orejuela izquierda y la pared libre de la $\mathrm{Al}$, quedando respetado el septo interauricular; y por otro lado, el «coconut atrium» cuando se afecta además este último ${ }^{2}$. En cuanto a la etiología de la calcificación, puede estar favorecida por el proceso inflamatorio inherente a la cardiopatía reumática o deberse al efecto de la sobrecarga de presión auricular originada por la estenosis mitral, que induce disfunción endotelial y al igual que en el proceso aterogénico podría ser un factor determinante para la calcificación. La importancia de dicha calcificación es que puede originar una deficiente compliance de la Al y en consecuencia una transmisión de las presiones auriculares elevadas hacia el lecho pulmonar, condicionando como en este caso hipertensión arterial pulmonar severa. Esta complicación puede ser reconocida fácilmente en la radiografía de tórax.

\footnotetext{
* Autor para correspondencia. Unidad de Cardiología. Hospital Universitario Fundación Alcorcon. C/Budapest n. ${ }^{\circ}$ 1, Alcorcón 28922 Madrid. Teléfono: +34 916219709 . Teléfono móvil: 646693072.

Correos electrónicos: problesve.pr@gmail.com, problesve@yahoo.es (P. Robles-Velasco).
} 


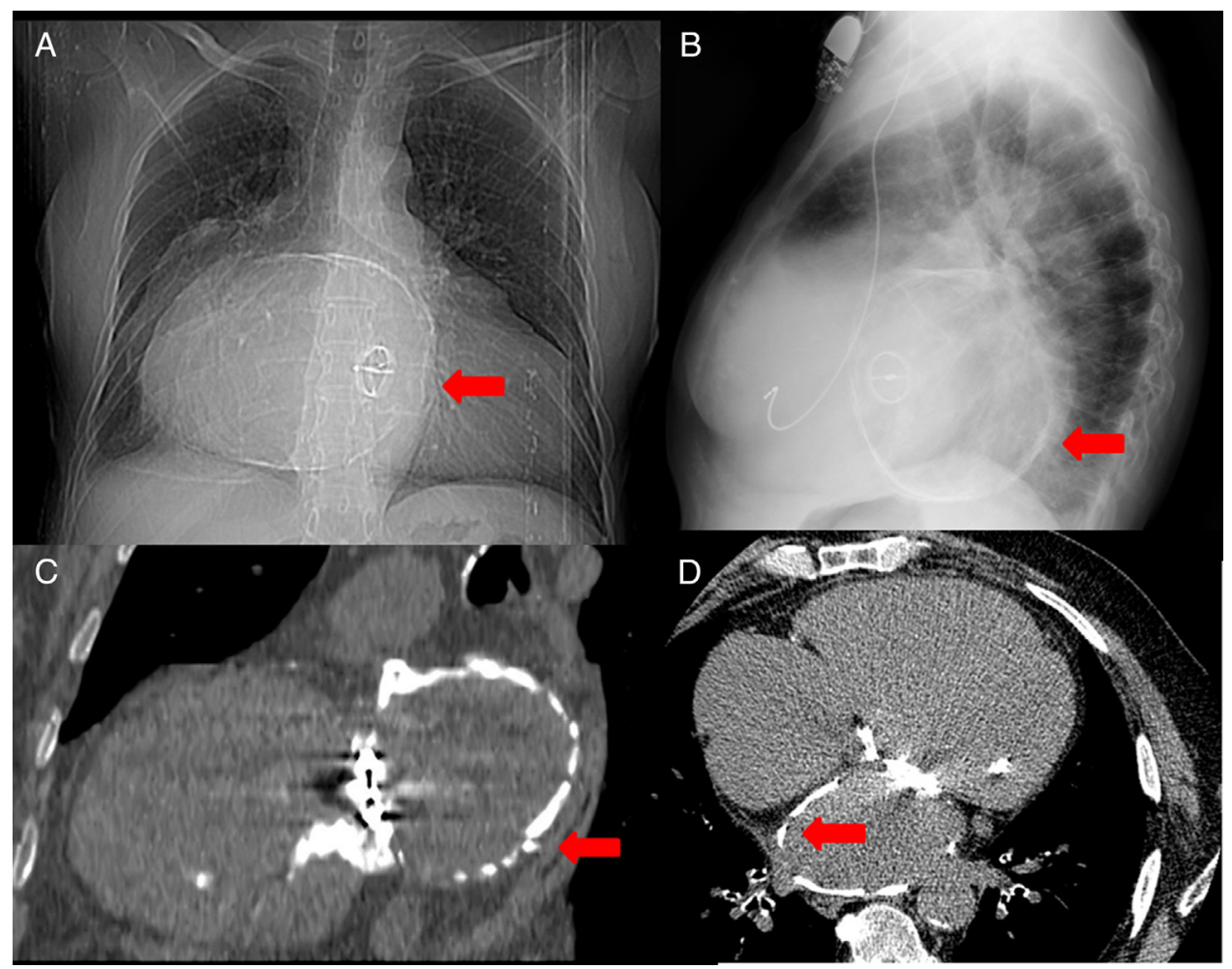

Figura 1 A: radiografía de tórax en posición anteroposterior que muestra una calcificación lineal (flecha roja) que contornea toda el área de la aurícula izquierda. B: radiografía de tórax en posición lateral que muestra la calcificación lineal (flecha roja) con la imagen de la prótesis mecánica en posición mitral. C: reconstrucción de TAC torácico sin contraste en plano de 2 cámaras cardiacas donde se visualiza la calcificación severa de toda la pared auricular (flecha roja). D: reconstrucción de TAC torácico sin contraste en plano de 4 cámaras cardiacas donde se visualiza la calcificación severa de la pared auricular incluyendo el septo interauricular (flecha roja).

\section{Responsabilidades éticas}

Protección de personas y animales. Los autores declaran que para esta investigación no se han realizado experimentos en seres humanos ni en animales.

Confidencialidad de los datos. Los autores declaran que en este artículo no aparecen datos de pacientes.

Derecho a la privacidad y consentimiento informado. Los autores declaran que en este artículo no aparecen datos de pacientes.

\section{Bibliografía}

1. Onishi T, Idei $\mathrm{Y}$, Otsui $\mathrm{K}$, et al. Coconut atrium in long-standing rheumatic valvular heart disease. Am J Case Rep. 2015;16:191-5, http://dx.doi.org/10.12659/AJCR.892449

2. Del Campo C, Weinstein P, Kunnelis C, et al. Coconut atrium: Transmural calcification of the entire left atrium. Tex Heart Inst J. 2000;27:49-51. 